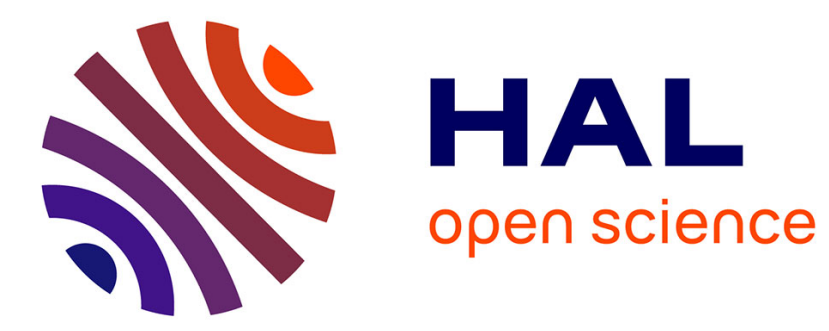

\title{
Emerging concepts in chromatin-level regulation of plant cell differentiation: timing, counting, sensing and maintaining
}

\author{
Daniel Bouyer, Ana Karina Morao, François Roudier
}

\section{- To cite this version:}

Daniel Bouyer, Ana Karina Morao, François Roudier. Emerging concepts in chromatin-level regulation of plant cell differentiation: timing, counting, sensing and maintaining. Current Opinion in Plant Biology, 2016, 34, pp.27 - 34. 10.1016/j.pbi.2016.07.010 . hal-02999283

\section{HAL Id: hal-02999283 \\ https://hal.science/hal-02999283}

Submitted on 14 Dec 2020

HAL is a multi-disciplinary open access archive for the deposit and dissemination of scientific research documents, whether they are published or not. The documents may come from teaching and research institutions in France or abroad, or from public or private research centers.
L'archive ouverte pluridisciplinaire HAL, est destinée au dépôt et à la diffusion de documents scientifiques de niveau recherche, publiés ou non, émanant des établissements d'enseignement et de recherche français ou étrangers, des laboratoires publics ou privés. 


\title{
Emerging concepts in chromatin-level regulation of plant cell differentiation: timing, counting, sensing and maintaining
}

\author{
Ana Karina Morao ${ }^{1}$, Daniel Bouyer ${ }^{1}$ and François Roudier ${ }^{1,2}$
}

\begin{abstract}
Plants are characterized by a remarkable phenotypic plasticity that meets the constraints of a sessile lifestyle and the need to adjust constantly to the environment. Recent studies have begun to reveal how chromatin dynamics participate in coordinating cell proliferation and differentiation in response to developmental cues as well as environmental fluctuations. In this review, we discuss the pivotal function of chromatin-based mechanisms in cell fate acquisition and maintenance, within as well as outside meristems. In particular, we highlight the emerging role of specific epigenomic factors and chromatin pathways in timing the activity of stem cells, counting cell divisions and positioning cell fate transitions by sensing phytohormone gradients.
\end{abstract}

\begin{abstract}
Addresses
${ }^{1}$ Institut de Biologie de l'Ecole Normale Supérieure, Centre National de la Recherche Scientifique (CNRS) UMR8197, Institut National de la Santé et de la Recherche Médicale (INSERM) U1024, Ecole Normale Supérieure, 46 rue d'Ulm, 75230 Paris Cedex 05, France

${ }^{2}$ Laboratoire de Reproduction et Développement des Plantes, Centre National de la Recherche Scientifique (CNRS) UMR5667, Institut National de la Recherche Agronomique (INRA) UMR879, Ecole Normale Supérieure de Lyon, Université Lyon 1 (UCBL), 46 Allée d'Italie, 69364 Lyon Cedex 07, France
\end{abstract}

Corresponding authors: Bouyer, Daniel (bouyer@biologie.ens.fr) and Roudier, François (roudier@biologie.ens.fr)

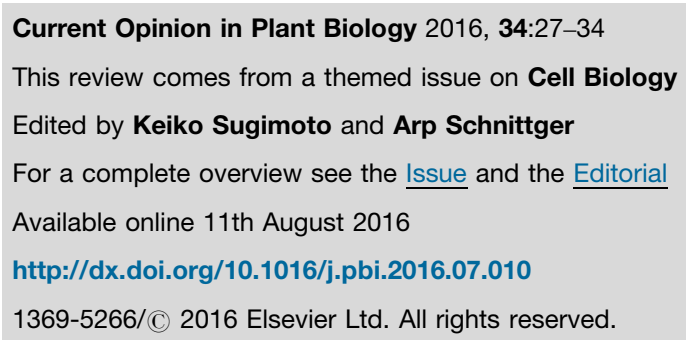

\section{Introduction}

Plant development mainly occurs post-embryonically and is characterized by continuous growth and extensive phenotypic plasticity. It relies primarily on the activity of stem cell populations that are maintained within the root and shoot meristems, and fuel the differentiation pathways leading to organ formation. Numerous studies have established that plant cell identity results from a tight interplay between transcriptional regulatory networks and phytohormonal signaling [1-3]. In contrast, the mechanisms regulating the progression of a cell along a differentiation path are still poorly understood.

In recent years, chromatin organization has emerged as an important player in the regulation of cell differentiation [4]. Chromatin-level orchestration of gene expression relies on covalent modifications of histones, incorporation of histone variants, DNA methylation and other factors, such as modifying and ATP-dependent remodeling enzymes (see Box 1). Combinations of these factors contribute to defining dynamic chromatin states that modulate accessibility to DNA regulatory regions and correlate with distinct transcriptional outcomes $[5,6]$. Whereas some chromatin states are quite transient, others can be perpetuated through replication (see Box 1). These differential dynamics are the basis of the two main properties achieved by chromatin during differentiation: plasticity, which is required to allow cell fate change by altering gene expression profiles through the selective action of cell type specific transcription factors (TFs), and heritability, which is necessary to maintain cell identity by stabilizing transcriptional states. In this review, we discuss recent studies, mostly in Arabidopsis, revealing how chromatin dynamics contributes to the coordination of cell division with differentiation as well as to the regulation of cell fate acquisition and maintenance in plants.

\section{Chromatin-level control of stem cell fate and activity}

Within meristems, stem cells are found in specific microenvironments known as stem cell niches (SCN), in which their pluripotent state is maintained by local signals coming from an organizing center (OC) [3,7]. The homeodomain transcription factors (TFs) WUSCHEL (WUS) and its homologue WUSCHEL RELATED HOMEOBOX 5 (WOX5) are key organizers of stem cell pools that maintain stem cell identity in the shoot (SAM) and root apical meristems (RAM), respectively [8,9]. Recent findings indicate that both the spatiotemporal regulation of WOX 5 and WUS expression and their repressive action on differentiation factors depend on specific chromatinbased mechanisms $\left[10^{\bullet}, 11^{\bullet \bullet}, 12^{\bullet \bullet}\right]$.

Restriction of WOX5 expression within the RAM OC, called the quiescent center $(\mathrm{QC})$, is regulated by the PHD-domain protein ROW1 (REPRESSOR OF WUS1). ROW1 is expressed in the proximal meristem, just above the QC (Figure 1). The binding of ROW1 to 


\section{Box 1 Chromatin factors and pathways}

Studies in the model plant Arabidopsis thaliana have provided important insights into chromatin components and regulatory pathways as well as epigenome organization. The basic unit of chromatin is the nucleosome, which is composed of a protein core of two molecules of the histones $\mathrm{H} 2 \mathrm{~A}, \mathrm{H} 2 \mathrm{~B}, \mathrm{H} 3$ and $\mathrm{H} 4$, around which $147 \mathrm{bp}$ of DNA is wrapped.

Several histone variants exist and provide specific indexing of the genome. For instance, H3.1 is incorporated during DNA replication and $\mathrm{H} 3.3$ is preferentially linked with transcription [56]. Additional variants of $\mathrm{H} 3$ or $\mathrm{H} 2 \mathrm{~A}$ are either exclusively found over pericentromeric heterochromatic regions such as H2A.W [57], at responsive genes (H2A.Z) [58] or only expressed during particular developmental phases, such as gametophyte-specific H3s [56]. Besides nucleosomal histones, linker $\mathrm{H} 1$ histones are important regulators of DNA accessibility $[59,60]$.

In addition, histones can be subject to a plethora of posttranslational modifications such as phosphorylation, ubiquitination, acetylation and methylation, which are found over several residues located mainly in their $\mathrm{N}$-terminal extremity. Whereas acetylation is correlated with gene expression and show rather fast kinetics [61], methylation of histones can be associated with active or repressive transcriptional states, depending on the modified residue. For instance, $\mathrm{H} 3 \mathrm{~K} 4 \mathrm{me} 3$ is associated with transcriptional activity, whereas $\mathrm{H} 3 \mathrm{~K} 9 \mathrm{me} 2$ is found primarily at silent transposable elements and H3K27me 3 marks genes repressed by the Polycomb Repressive Complex 2 (PRC2). PRC2 is evolutionary conserved and regulates most developmental phase transitions in plants through the maintenance of a repressive state [62]. In comparison to active marks, H3K27me3 and H3K9me2 tend to have lower turnover rates [61]. Moreover, H3K27me3 propagation across DNA replication through continuous modification of both parental and newly incorporated histones represents a specific mode of maintenance, which reflects the central role of PRC2-mediated gene repression in cellular memory [51]. H3K27me3 removal can be achieved either by passive, replication-coupled dilution or via the activity of specific demethylases $[63,64]$.

DNA methylation $(5 \mathrm{mC})$ is another key epigenetic mark involved in the control of transposable element activity and the regulation of gene expression, which, in plants, is found in all sequence contexts through the activity of distinct enzymatic pathways $[65,66]$. RNA directed DNA methylation (RdDM) is a plant-specific pathway that relies on the action of small interfering RNAs (siRNAs) generated via distinct pathways $[48,67]$. Sequence-specific targeting of DNA methyltransferases via these siRNAs is particularly important for de novo methylation of repeat sequences [68].

H3K4me3 marks present at the WOX5 promoter region has been proposed to block WOX5 transcription in adjacent cell layers located shootward to the QC $\left[10^{\circ}\right]$. Indeed, loss of ROW1 leads to an enlargement of the WOX5 expression domain accompanied by defects in cell differentiation. Similarly, row1 mutants show ectopic expression of WUS resulting in severe SAM defects [13]. In the SAM however, ROW1 directly binds to $W U S$ regulatory DNA where it is proposed to compete with the SWI/SNF chromatin remodeler SPLAYED in order to prevent WUS transcription outside of the SAM OC [13,14]. Since WOX5 and WUS are functionally interchangeable [9], it would be interesting to determine if the binding of ROW1 at the WUS locus also relies on the recognition of
H3K4me3 or whether the ability of ROW1 to repress stem cell organizers is based on different mechanisms in the root and shoot meristems.

In addition to sustaining continuous organogenesis by stem cell maintenance, chromatin-level regulation of WUS also controls the transition towards determinate growth in the floral meristem. Termination of the floral stem cell pool through the stable repression of $W U S$ occurs in two consecutive steps. At an early stage, the homeotic TF AGAMOUS (AG) recruits Polycomb repressive complex 2 (PRC2) to the WUS locus, thus initiating its downregulation via the deposition of the repressive H3K27me3 mark [15]. Full repression of WUS is only achieved two days later through the repressive action of KNUCKLES $(K N U)$, which encodes a zinc finger protein. Activation of $K N U$ depends on $\mathrm{AG}$, which in this case triggers the eviction of PRC2 from $K N U$, thus leading to the progressive dilution of $\mathrm{H} 3 \mathrm{~K} 27 \mathrm{me} 3$ across replication cycles $\left[11^{\bullet \bullet}\right]$. Thus, the chromatin-assisted delayed activation of $K N U$ allows precise timing of SC termination and simultaneously provides a counting mechanism to establish the proper number of mitosis necessary for floral organ formation. It remains to be understood how the same TF is able in a very similar cell population to recruit and evict PRC2 from distinct genes, promoting or preventing H3K27me3 deposition, respectively.

Accumulating evidence indicates that WUS and WOX5 act in turn as repressors of differentiation factors in stem cells in a chromatin-dependent manner. WOX5 has been shown to move from the QC to adjacent columella stem cells (CSC) where it represses the differentiation factor CYCLING DOF FACTOR 4 (CDF4) by recruiting the co-repressor TOPLESS (TPL) and the histone deacetylase HDA19 (Figure 1) [12 $\left.{ }^{\bullet \bullet}\right]$. Formation of this repressive deacetylation complex is limited to the CSC as $C D F 4$ is expressed in the differentiating daughter cell, revealing the remarkable spatial precision of this process. Since WUS also interacts with TPL in the SAM [16], recruitment of a TPL-HDAC19 complex could represent a general mechanism to repress differentiation-promoting genes in stem cells.

In addition to its role in stem cell maintenance, chromatin-level regulation is also required to repress pluripotency genes outside $\mathrm{SCNs}$ in order to allow cell differentiation. For instance, the ASYMMETRIC LEAVES complex recruits PRC2 to the promoters of cell proliferation factors at the SAM boundaries, leading to their sustained repression during leaf primordia formation and subsequent growth [17]. More generally, PRC2 is critical to maintain meristem activity and orchestrate differentiation processes over time but is largely dispensable for meristem establishment during embryogenesis [18]. 


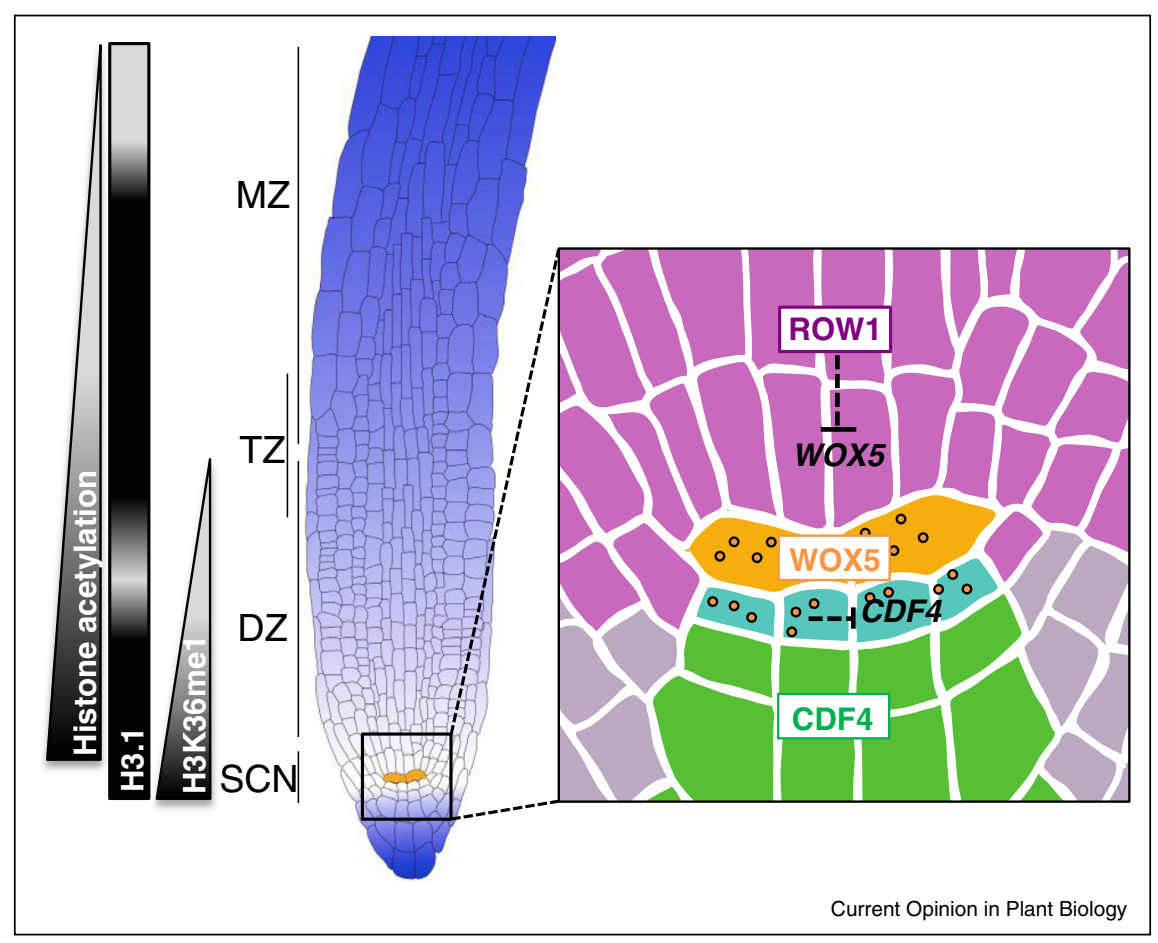

Chromatin-level regulation of cell differentiation within the root apical meristem. Root growth homeostasis largely depends on the tight coordination between the activity of the stem cell niche (SCN), cell production in the division zone (DZ) and cell elongation as well as enddifferentiation within the transition (TZ) and maturation zone (MZ). Both this shootward and the columella differentiation gradients are highlighted in purple. Stem cell maintenance requires the activity of WOX5 whose expression is confined to the quiescent, organizing center (QC) by the binding of ROW1 to H3K4me3 marks at the WOX5 promoter in adjacent cell files. In turn, WOX5 movement from the QC to columella stem cells (turquoise) leads to direct repression of the CDF4 differentiation factor through the recruitment of a histone deacetylase complex. Transition from the division to the maturation zone is accompanied by a reduction of histone mobility and acetylation levels, as well as the rapid eviction of histone H3.1 after the last mitotic and endoreplication cycles in the DZ and MZ, respectively. The progressive reduction of H3K36me1 levels upon each replication cycle is proposed to participate in counting the remarkably stable number of mitosis within the DZ. Expression domains of WOX5, ROW1 and CDF4 are indicated in orange, pink and green, respectively.

\section{Spatiotemporal chromatin-level regulation of cell fate transitions}

Histone acetylation dynamics play an important role in translating auxin gradients into position-dependent cell fate switches during flower organogenesis. Under low auxin conditions, TPL bound to the histone deacetylase HDA19 forms a complex with Aux/IAA proteins that interacts with the MONOPTEROS/AUXIN RESPONSE FACTOR 5 (MP/ARF5) [19], thereby preventing the expression of MP targets. Higher auxin levels lead to Aux/IAA proteolysis, thus enabling MP to recruit the SWI/SNF family members SPLAYED (SYD) and BRAHMA (BRM). Remodeling of the deacetylated, repressive chromatin state into a more accessible, transcription-prone environment at MP targets then promotes flower primordium initiation $\left[20^{\bullet \bullet}\right]$. This 'opening' of chromatin likely favors in turn the binding of additional TFs and the recruitment of histone acetyltransferase activity to sustain the transcriptional activation of auxin responsive genes, as previously reported for bZIP TFs [21]. As auxin graded distribution is a major orchestrator of cell fate transitions
[1-3], one can expect that this chromatin switch represents a common theme during plant organogenesis, coupling phytohormone-driven transcriptional output and positional cues.

Several studies have exploited the relatively simple functional organization of the Arabidopsis root in order to monitor the dynamics of chromatin factors during the differentiation process (Figure 1). Earlier work suggested that local chromatin accessibility is rapidly altered in cells sensing new positional cues within the meristem [22]; the signaling and mechanistic pathways involved remain to be characterized.

Comparisons between the DNA methylome of different root cell types revealed some variations that had little impact on gene expression, suggesting that the role of DNA methylation dynamics in regulating transcriptional programs within somatic cells is rather limited [23 $3^{\circ}$. Of note, columella cells located at the tip showed the highest methylation levels among investigated cell types, mainly 
at $\mathrm{CHH}$ sites over TE sequences, suggesting strong RNA-directed DNA methylation (RdDM) activity (see Box 1). Indeed, overaccumulation of 24-nt small RNA was accompanied with increased expression of $\mathrm{RdDM}$ components, the activity of which might be facilitated by a global decrease in heterochromatin compaction, as suggested by the absence of the nucleosome remodeller DEGREASED DNA METHYLATION 1 (DDM1) and the downregulation of $\mathrm{H} 1$ and $\mathrm{H} 2 \mathrm{~A} . \mathrm{W}$ histone variants $\left[23^{\circ}\right]$.

Imaging-based quantification of nucleosome dynamics along the root differentiation gradient (Figure 1) indicated that histone H2B mobility diminishes concomitantly with acetylation levels as cells transit from the division to the maturation zone $\left[24^{\circ}\right]$. Furthermore, cells reaching the limit of the division zone are characterized by an abrupt depletion of the replication-dependent histone H3.1 variant $\left[25^{\circ}\right]$. Eviction of this variant is also observed in cells of the maturation zone that are terminating their endoreplication cycles, which suggests a general link between H3.1 dynamics and the replication potential of cells during

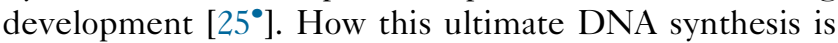
programmed remains to be determined, but the fact that the number of cells is remarkably stable within the division zone suggests the existence of mechanisms that count

Figure 2

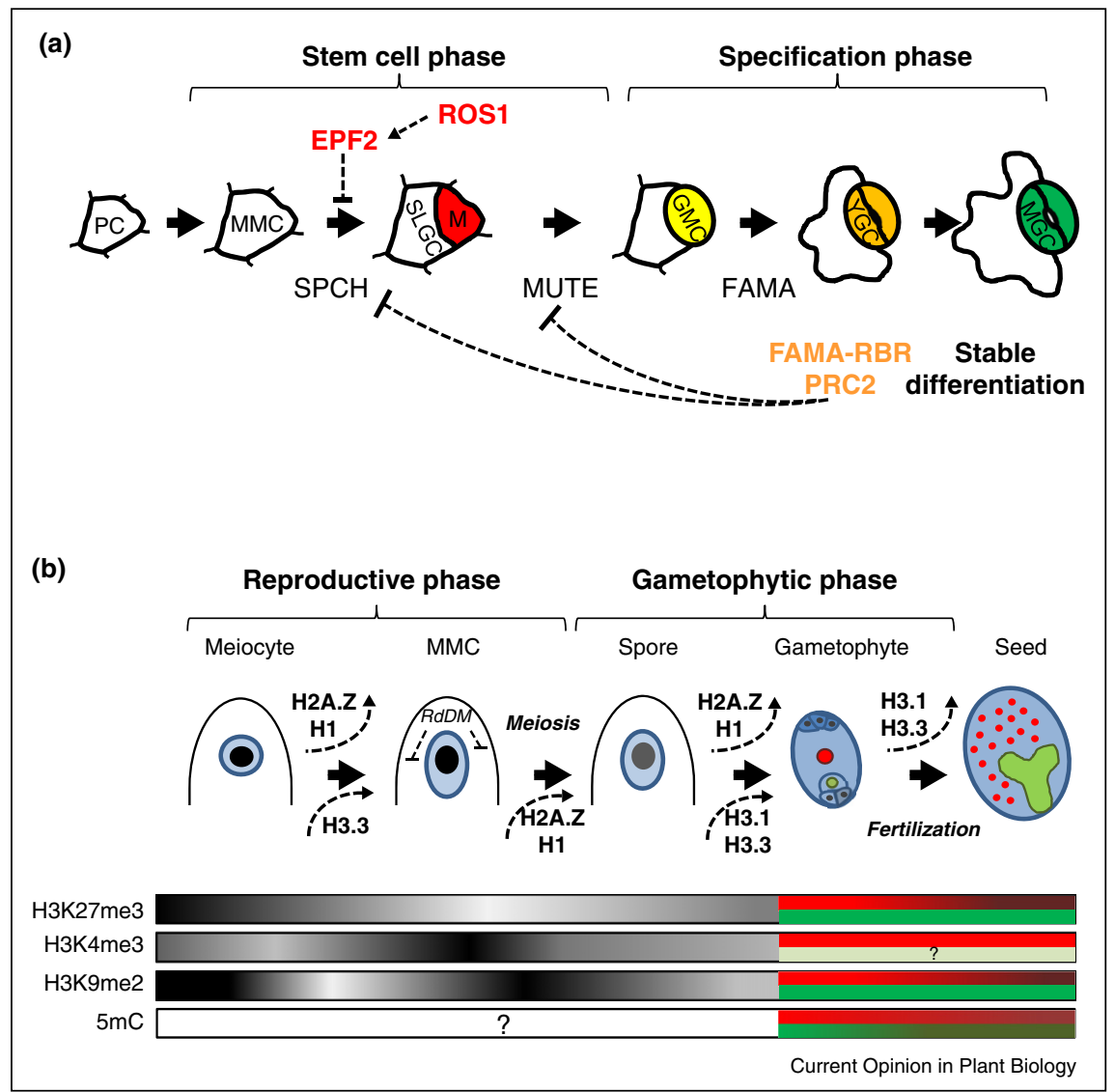

Chromatin dynamics during the differentiation of lineage-committed cells. (a) Stomatal lineage initiates with the asymmetric division of a meristemoid mother cell (MMC) that derives from a protodermal leaf cell (PC), resulting in the generation of a stomata stem cell-like meristemoid (M) and a larger stomatal lineage ground cell (SLGC). M further differentiates into a guard mother cell (GMC), which divides symmetrically to form the two young (YGC) and then mature (MGC) guard cells. ROS1-dependent expression of EPF2 in M cells prevents the differentiation of adjacent SLGC into additional M cells thus participating in leaf epidermis patterning between stomata and pavement cells. While DNA methylation dynamics likely affects the plasticity of the stomatal lineage, repression of stem cell phase regulators by PRC2 in guard cells ensures robust fate commitment. (b) Female germline establishment starts with the differentiation of a subepidermal cell within the ovule primordium into a megaspore mother cell (MMC). Fate transitions are associated with successive waves of eviction of H2A.Z and $\mathrm{H} 1$ histones as well as incorporation of stagespecific H3.1 and H3.3 variants, specifically expressed during the reproductive or gametophytic phase. Differentiation of the MMC is restricted by the non-cell autonomous action of RdDM pathway components. Following meiosis, the resulting spore divides and differentiates into four different cell types including the egg cell (EC, green) and the central cell (CC, red), which represent the female gametes. Concomitantly to histone variant replacement, the spore-to-gametophyte transition is also potentially controlled by RdDM. In addition, variation in the abundance of specific chromatin marks occurs during the reproductive and gametophytic phases (grey heatmap). Upon fertilization, the gametophyte-specific histone $\mathrm{H} 3$ variants are finally exchanged with somatic $\mathrm{H} 3$ variants in the embryo and endosperm, which are characterized by distinct epigenomes. 
mitotic or replication cycles. By analogy with the delayed activation of $K N U$ mentioned above $\left[11^{\bullet \bullet}\right.$ ], a chromatindilution model has been proposed whereby H3K36me1 levels, specifically deposited in the SCN by the SETdomain protein ASH1-RELATED3 (ASHR3), would passively decrease upon each cell division, reaching depletion after about four rounds of replication, when cells enter the transition zone [26].

\section{Chromatin-based regulation in lineage- committed cells}

Besides the activity of stem cell pools within meristems, de novo generation of specialized cell lineages such as stomatal differentiation at the surface of above-ground organs is also critical for tissue functioning. Stomatal development occurs in two phases: an early stem cell phase leading to the generation of a meristemoid (M) cell through asymmetric division, followed by a specification phase ending with the formation of a pair of stomatal guard cells, which are involved in gaz exchange regulation (Figure 2a). Fate transitions during stomatal development are controlled by the sequential activity of the bHLH transcription factors SPEECHLESS (SPCH), MUTE and FAMA among other factors such as EPIDERMAL PATTERNING FACTOR 2 (EPF2) [27,28]. During M cell differentiation, active demethylation of the EPF2 promoter by the DNA glycosylase/lyase ROS1 leads to EPF2 expression, which acts as a negative regulator of meristemoid mother cell (MMC) fate through the downregulation of $S P C H\left[29^{\circ}\right]$. In addition, $S P C H$ and $F A M A$ are directly targeted by RdDM and repressed under low humidity conditions [30]. These findings indicate that transcriptional regulation by DNA methylation affects stomatal initiation at different levels, thus providing developmental flexibility in response to environmental cues (Figure 2a). CHH methylation has also been shown to influence differentiation and growth of epidermal fiber cells in cotton $[31,32]$.

At the other end of the stomatal lineage, PRC2-mediated gene repression plays an important role in maintaining stable fate commitment of guard cells. Indeed, altering the expression pattern of FAMA, a master regulator of guard cell identity, leads to the failure of lineage termination and the generation of stoma within stoma [33]. Reiteration of this transcriptional program was linked with incomplete PRC2-mediated repression of the stem cell-like regulator SPCH and MUTE genes within guard cells. Interestingly, interfering with the ability of FAMA to recruit the RETINOBLASTOMA-RELATED (RBR) repressor protein at early stomatal lineage genes leads to a similar reiteration phenotype [34]. This suggests that binding of the FAMA-RBR complex recruits PRC2 at stomata-promoting TFs during late differentiation stages, thus enforcing the stable acquisition of guard cell identity [35]. To which extent these events are correlated with the observed depletion of histone H3.1 towards the end of guard cell differentiation $\left[25^{\circ}\right]$ needs to be determined.

In keeping with this model, the critical role of PRC2 activity in maintaining the identity of fully differentiated cells was recently highlighted $\left[36^{\bullet \bullet}\right]$. Thus, whereas epidermal root hairs reach full specification in the absence of PRC2, they undergo several rounds of mitosis despite their polyploidy and revert back to an unorganized, dedifferentiated cell mass, from which embryoid structures occasionally arise. Other mature cell types are affected in a similar way, suggesting that PRC2 acts as a general repressor of a dedifferentiation potential that is retained in mature cells $\left[36^{\circ \bullet}\right]$. Further work will help determining whether these phenotypes are caused primarily by the deregulation of $L E C 2$-dependent embryonic programs, reentry into mitosis or other processes controlled by PRC2.

Extensive chromatin dynamics occur during the differentiation of male and female germline cells $\left[37,38^{\bullet}, 39\right]$. On the female side, meiocyte differentiation into the megaspore mother cell (MMC) is accompanied by chromatin decondensation, reduction of marks associated with pericentromeric heterochromatin (see Box 1) as well as of $\mathrm{H} 3 \mathrm{~K} 27 \mathrm{me} 3$. Fate transitions in the reproductive and gametophytic phases are characterized by successive rounds of eviction of the variant histone H2A.Z as well as of the linker histone $\mathrm{H} 1$ and the incorporation of stagespecific H3.3 variants (Figure 2b). In addition, RdDM prevents the differentiation of surrounding cells into the MMC fate in both Arabidopsis and maize [40]. RdDM is also likely involved at the spore-to-gametophyte transition that leads to the formation of the two female gametes, the egg cell (EC) and the homo-diploid central cell (CC) [41]. These cells, and their respective fertilization products, the embryo and endosperm, have contrasted epigenomes at the cytological and molecular level. Thus, in comparison to the EC, the CG has low levels of H3K9me2 and DNA methylation, which was shown to depend on the DNA demethylase DME and to be functionally important for endosperm differentiation [42-44]. Conversely, H3K9me2 deposition in the EC seems important for early embryogenesis [45]. CG differentiation and development into endosperm is also regulated by PRC2 [46], a mechanism that appears evolutionary conserved even in plants where the gametophyte represents the dominant phase [47].

Despite these extensive dynamics, alterations of the chromatin modifiers involved have rather subtle developmental defects, which questions the relevance of chromatin-based mechanisms in germline differentiation. Although this role is potentially blurred by redundant layers of regulatory processes [48], such sequential chromatin changes might also serve as an epigenetic reprogramming step to start a new life cycle with a fresh 
potential, unperturbed by the progenitors' history $[49,50]$.

\section{Conclusions and prospects}

Recent findings have started to unveil key roles for chromatin-based mechanisms in establishing, fine-tuning and maintaining transcriptional patterns during cell differentiation. Accumulating evidence indicate that such regulations are important to achieve both developmental flexibility and robust fate commitment in time and space.

Within meristems, high chromatin state dynamics relay TF-driven decisions and phytohormonal cues by sensing signaling gradients, thus participating in the temporal stabilization of cell identities as well as the promotion of cell fate progression or switches in a position-dependent manner. This progression needs to be coupled with DNA replication, both during mitotic and endoreplication cycles, that likely represents a window of opportunity to modify the chromatin landscape and rewire cell fate [51]. Indeed, recent evidence in Drosophila reveals extensive remodeling of chromatin organization upon replication, especially at transcriptionally active genes [52]. Although this remains to be explored in plants, replication-associated dilution of chromatin marks has been shown to couple the timing of stem cell termination with the counting of mitosis during floral organ formation; a mechanism that was also proposed to account for the regulation of cell number within the RAM, which requires further investigation.

Outside the meristem and its predominant signaling environment, chromatin-level regulation is essential to maintain stable fate commitment, possibly independently of preceding patterning mechanisms. This has been exemplified by the role of PRC2 activity in preventing 'slipping back' into previous differentiation stages or earlier developmental programs, during late stomata or root hair differentiation, for instance.

Overall, our understanding of how chromatin-based mechanisms are integrated within developmental regulatory networks and how transcriptional decisions are maintained through replication is still very limited. Combination of quantitative live imaging techniques with cell-type specific and single cell (epi)genomic approaches [53-55] will be instrumental in outlining the regulatory principles that underpin the fascinating complexity of plant cell differentiation.

\section{Acknowledgements}

We thank V. Colot, L. Quadrana and E. Caillieux for critical reading of the manuscript. Research in the author's laboratory was supported by the European Union Seventh Framework Programme Network of Excellence EpiGeneSys (HEALTH-F4-2010-257082), the CNRS and the Agence Nationale de la Recherche. A.K.M. is the recipient of a doctoral grant from the French Ministère de la Recherche et de l'Enseignement Supérieur.

\section{References and recommended reading}

Papers of particular interest, published within the period of review, have been highlighted as:

- of special interest

-. of outstanding interest

1. Clark NM, de Luis Balaguer MA, Sozzani R: Experimental data and computational modeling link auxin gradient and development in the Arabidopsis root. Front Plant Sci 2014, 5:328.

2. Takatsuka $\mathrm{H}$, Umeda M: Hormonal control of cell division and elongation along differentiation trajectories in roots. J Exp Bot 2014, 65:2633-2643.

3. Gaillochet C, Lohmann JU: The never-ending story: from pluripotency to plant developmental plasticity. Development 2015, 142:2237-2249.

4. Ikeuchi M, Iwase A, Sugimoto K: Control of plant cell differentiation by histone modification and DNA methylation. Curr Opin Plant Biol 2015, 28:60-67.

5. Roudier F, Ahmed I, Bérard C, Sarazin A, Mary-Huard T, Cortijo S, Bouyer D, Caillieux E, Duvernois-Berthet E, Al-Shikhley L et al.: Integrative epigenomic mapping defines four main chromatin states in Arabidopsis. EMBO J 2011, 30:1928-1938.

6. Sequeira-Mendes J, Araguez I, Peiro R, Mendez-Giraldez R, Zhang X, Jacobsen SE, Bastolla U, Gutierrez C: The functional topography of the Arabidopsis genome is organized in a reduced number of linear motifs of chromatin states. Plant Cell 2014, 26:2351-2366.

7. Heidstra R, Sabatini S: Plant and animal stem cells: similar yet different. Nat Rev Mol Cell Biol 2014, 15:301-312.

8. Mayer KF, Schoof H, Haecker A, Lenhard M, Jurgens G, Laux T: Role of WUSCHEL in regulating stem cell fate in the Arabidopsis shoot meristem. Cell 1998, 95:805-815.

9. Sarkar AK, Luijten M, Miyashima S, Lenhard M, Hashimoto T, Nakajima K, Scheres B, Heidstra R, Laux T: Conserved factors regulate signalling in Arabidopsis thaliana shoot and root stem cell organizers. Nature 2007, 446:811-814.

10. Zhang $Y$, Jiao $Y$, Liu Z, Zhu YX: ROW1 maintains quiescent - $\quad$ centre identity by confining WOX5 expression to specific cells. Nat Commun 2015, 6:6003.

In this work, ROW1 is identified as a repressor of WOX5 in cell layers located immediately above the quiescent center, through direct binding of $\mathrm{H} 3 \mathrm{~K} 4 \mathrm{me} 3$ marks at the WOX5 promoter. This mechanism enables swift downregulation of WOX5 in stem cells and their immediate daughters thus confining WOX5 transcription to the quiescent center.

11. Sun B, Looi LS, Guo S, He Z, Gan ES, Huang J, Xu Y, Wee WY

-. Ito T: Timing mechanism dependent on cell division is invoked by Polycomb eviction in plant stem cells. Science 2014 343:1248559.

The authors reveal how stem cell termination is precisely timed within the floral meristem via the delayed repression of WUS. AG, the expression of which is activated by WUS, binds to the promoter of KNU leading to the eviction of PRC2. Within two days, progressive loss of H3K27me3 upon cell divisions enables KNU expression, which results in WUS repression. This landmark article coins the concept of epigenetic timer as well as mitotic counter that provides the precise number of cells required for organ formation.

12. Pi L, Aichinger E, van der Graaff E, Llavata-Peris $\mathrm{Cl}$, Weijers $\mathrm{D}$,

-. Hennig L, Groot E, Laux T: Organizer-derived WOX5 signal maintains root columella stem cells through chromatinmediated repression of CDF4 expression. Dev Cell 2015, 33:576-588.

The authors provide evidence that WOX5 moves from the quiescent center to columella stem cells, acting as a mobile signal to maintain their identity by repressing the differentiation factor CDF4. They show that WOX5 recruits TOPLESS and HDA19, which deacetylates the promoter of CDF4 thus preventing its expression in a cell type-specific manner.

13. Han P, Li Q, Zhu YX: Mutation of Arabidopsis BARD1 causes meristem defects by failing to confine WUSCHEL expression to the organizing center. Plant Cell 2008, 20:1482-1493. 
14. Kwon CS, Chen C, Wagner D: WUSCHEL is a primary target for transcriptional regulation by SPLAYED in dynamic control of stem cell fate in Arabidopsis. Genes Dev 2005, 19:992-1003.

15. Liu X, Kim YJ, Muller R, Yumul RE, Liu C, Pan Y, Cao X, Goodrich J, Chen X: AGAMOUS terminates floral stem cell maintenance in Arabidopsis by directly repressing WUSCHEL through recruitment of Polycomb Group proteins. Plant Cell 2011, 23:3654-3670.

16. Kieffer M, Stern Y, Cook H, Clerici E, Maulbetsch C, Laux T, Davies B: Analysis of the transcription factor WUSCHEL and its functional homologue in Antirrhinum reveals a potential mechanism for their roles in meristem maintenance. Plant Cell 2006, 18:560-573

17. Lodha M, Marco CF, Timmermans MC: The ASYMMETRIC LEAVES complex maintains repression of KNOX homeobox genes via direct recruitment of Polycomb-repressive complex2. Genes Dev 2013, 27:596-601.

18. Bouyer D, Roudier F, Heese M, Andersen ED, Gey D, Nowack MK, Goodrich J, Renou JP, Grini PE, Colot V et al.: Polycomb repressive complex 2 controls the embryo-to-seedling phase transition. PLoS Genet 2011, 7:e1002014.

19. Szemenyei H, Hannon M, Long JA: TOPLESS mediates auxindependent transcriptional repression during Arabidopsis embryogenesis. Science 2008, 319:1384-1386.

20. Wu MF, Yamaguchi N, Xiao J, Bargmann B, Estelle M, Sang Y,

- Wagner D: Auxin-regulated chromatin switch directs acquisition of flower primordium founder fate. Elife 2015, 4:e09269.

The authors identified the molecular bases for auxin-dependent activation of MP targets and flower primordia initiation. They provide evidence that in condition of high auxin, degradation of AUX/IAA proteins bound to MP leads to the eviction of the TPL-HDA19 repressive complex and the recruitment of BRM and SYD. The resulting chromatin state enables gene expression of MP targets, thus linking graded auxin distribution and positional cues with specific transcriptional output.

21. Weiste C, Droge-Laser W: The Arabidopsis transcription factor bZIP11 activates auxin-mediated transcription by recruiting the histone acetylation machinery. Nat Commun 2014, 5:3883.

22. Costa S, Shaw P: Chromatin organization and cell fate switch respond to positional information in Arabidopsis. Nature 2006 439:493-496.

23. Kawakatsu T, Stuart T, Valdes M, Breakfield N, Schmitz RJ,

- Nery JR, Urich MA, Han X, Lister R, Benfey PN et al.: Unique celltype-specific patterns of DNA methylation in the root meristem. Nat Plants 2016, 2:16058.

This article reports whole-genome methylation, mRNA and small RNA profiles of six Arabidopsis root cell types, which represent the first cell type-specific methylomes in plants. In contrast to transcriptome differences that correlate with cell lineages, methylome variations are preferentially linked with cell position in the root. Columella cells show extraordinarily high methylation levels, especially in the $\mathrm{CHH}$ context, suggesting strong RdDM activity in this cells.

24. Rosa S, Ntoukakis V, Ohmido N, Pendle A, Abranches R, Shaw P:

- Cell differentiation and development in Arabidopsis are associated with changes in histone dynamics at the single-cell level. Plant Cell 2014, 26:4821-4833.

Fluorescent Recovery After Photobleaching (FRAP) experiments reveal that histone mobility decreases along the root differentiation gradient concomitantly with acetylation levels.

25. Otero S, Desvoyes B, Peiro R, Gutierrez C: Histone H3 dynamics

- reveal domains with distinct proliferation potential in the Arabidopsis root. Plant Cell 2016.

The authors demonstrate that cells entering their last round of mitotic or endoreplication cycle are depleted in the S-phase-dependent histone H3.1 variant. This indicates that committment to differentiation and fate transitions in somatic cells show specific histone variant dynamics.

26. Kumpf R, Thorstensen T, Rahman MA, Heyman J, Nenseth $H Z$, Lammens T, Herrmann U, Swarup R, Veiseth SV, Emberland G et al.: The ASH1-RELATED3 SET-domain protein controls cell division competence of the meristem and the quiescent center of the Arabidopsis primary root. Plant Physiol 2014 , 166:632-643.
27. Pillitteri LJ, Torii KU: Mechanisms of stomatal development. Annu Rev Plant Biol 2012, 63:591-614.

28. Lau OS, Bergmann DC: Stomatal development: a plant's perspective on cell polarity, cell fate transitions and intercellular communication. Development 2012, 139:3683-3692.

29. Yamamuro C, Miki D, Zheng Z, Ma J, Wang J, Yang Z, Dong J,

- Zhu JK: Overproduction of stomatal lineage cells in Arabidopsis mutants defective in active DNA demethylation. Nat Commun 2014, 5:4062.

The authors show that loss of active DNA demethylation in a mutant of the DNA glycosylase ROS1 results in the overproduction of stomata cells in Arabidopsis leaves. Active removal of 5-methylcytosine at the promoter of EPF2 enables its expression in differentiating meristemoid cells, which is proposed to inhibit the differentiation of neighbouring cells into additional meristemoid cells.

30. Tricker PJ, Gibbings JG, Rodriguez Lopez CM, Hadley P, Wilkinson MJ: Low relative humidity triggers RNA-directed de novo DNA methylation and suppression of genes controlling stomatal development. J Exp Bot 2012, 63:3799-3813.

31. Song Q, Guan X, Chen ZJ: Dynamic roles for small RNAs and DNA methylation during ovule and fiber development in allotetraploid cotton. PLoS Genet 2015, 11:e1005724.

32. Wang M, Wang P, Tu L, Zhu S, Zhang L, Li Z, Zhang Q, Yuan D, Zhang $X$ : Multi-omics maps of cotton fibre reveal epigenetic basis for staged single-cell differentiation. Nucleic Acids Res 2016, 44:4067-4079.

33. Lee E, Lucas JR, Goodrich J, Sack FD: Arabidopsis guard cell integrity involves the epigenetic stabilization of the FLP and FAMA transcription factor genes. Plant J 2014, 78:566-577.

34. Matos JL, Lau OS, Hachez C, Cruz-Ramirez A, Scheres B, Bergmann DC: Irreversible fate commitment in the Arabidopsis stomatal lineage requires a FAMA and RETINOBLASTOMARELATED module. Elife 2014:3.

35. Kuwabara A, Gruissem W: Arabidopsis RETINOBLASTOMARELATED and Polycomb group proteins: cooperation during plant cell differentiation and development. J Exp Bot 2014, 65:2667-2676.

36. Ikeuchi M, Iwase A, Rymen B, Harashima H, Shibata M,

-• Ohnuma M, Breuer C, Morao AK, de Lucas M, De Veylder L: PRC2 represses dedifferentiation of mature somatic cells in Arabidopsis. Nat Plants 2015:1.

Characterization of genetic alterations resulting in ectopic proliferation of mature cells led the authors to demonstrate the critical requirement of PRC2 activity in maintaining terminal cell fate. Although root hairs reach full differentiation in the absence of PRC2, they resume cell division and further develop into calli with occasional embryo formation. The authors provide evidence that PRC2 suppresses dedifferentation of mature cells by repressing at least two developmental pathways involving WIND3 and LEC2, respectively.

37. Kawashima $T$, Berger $F$ : Epigenetic reprogramming in plant sexual reproduction. Nat Rev Genet 2014, 15:613-624.

38. She W, Grimanelli D, Rutowicz K, Whitehead MW, Puzio M,

- Kotlinski M, Jerzmanowski A, Baroux C: Chromatin reprogramming during the somatic-to-reproductive cell fate transition in plants. Development 2013, 140:4008-4019.

The authors use extensive cytological methods to demonstrate largescale chromatin reprogramming during female germline establishment. In addition to variations of specific chromatin marks over nucleosomal histones, this differentiation process is characterized by an overall depletion of the $\mathrm{H} 1$ linker histone.

39. Borg M, Berger F: Chromatin remodelling during male gametophyte development. Plant J 2015, 83:177-188.

40. Olmedo-Monfil V, Duran-Figueroa N, Arteaga-Vazquez M, Demesa-Arevalo E, Autran D, Grimanelli D, Slotkin RK, Martienssen RA, Vielle-Calzada JP: Control of female gamete formation by a small RNA pathway in Arabidopsis. Nature 2010, 464:628-632.

41. Tucker MR, Okada T, Hu Y, Scholefield A, Taylor JM, Koltunow AM: Somatic small RNA pathways promote the mitotic events of megagametogenesis during female reproductive development in Arabidopsis. Development 2012, 139:1399-1404. 
42. Pillot M, Baroux C, Vazquez MA, Autran D, Leblanc O, VielleCalzada JP, Grossniklaus U, Grimanelli D: Embryo and endosperm inherit distinct chromatin and transcriptional states from the female gametes in Arabidopsis. Plant Cell 2010 22:307-320.

43. Ibarra CA, Feng X, Schoft VK, Hsieh TF, Uzawa R, Rodrigues JA, Zemach A, Chumak N, Machlicova A, Nishimura T et al.: Active DNA demethylation in plant companion cells reinforces transposon methylation in gametes. Science 2012, 337:1360-1364.

44. Moreno-Romero J, Jiang H, Santos-Gonzalez J, Kohler C: Parental epigenetic asymmetry of PRC2-mediated histone modifications in the Arabidopsis endosperm. Embo J 2016.

45. Autran D, Baroux C, Raissig MT, Lenormand T, Wittig M, Grob S, Steimer A, Barann M, Klostermeier UC, Leblanc O et al.: Maternal epigenetic pathways control parental contributions to Arabidopsis early embryogenesis. Cell 2011, 145:707-719.

46. Rodrigues JA, Zilberman D: Evolution and function of genomic imprinting in plants. Genes Dev 2015, 29:2517-2531.

47. Pereman I, Mosquna A, Katz A, Wiedemann G, Lang D, Decker EL, Tamada Y, Ishikawa T, Nishiyama T, Hasebe M et al.: The Polycomb group protein CLF emerges as a specific trimethylase of H3K27 regulating gene expression and development in Physcomitrella patens. Biochim Biophys Acta 2016, 1859:860-870.

48. Creasey KM, Zhai J, Borges F, Van Ex F, Regulski M, Meyers BC, Martienssen RA: miRNAs trigger widespread epigenetically activated siRNAs from transposons in Arabidopsis. Nature 2014, 508:411-415.

49. Heard E, Martienssen RA: Transgenerational epigenetic inheritance: myths and mechanisms. Cell 2014, 157:95-109.

50. Iwasaki $M$ : Chromatin resetting mechanisms preventing transgenerational inheritance of epigenetic states. Front Plant Sci 2015, 6:380.

51. Alabert C, Barth TK, Reveron-Gomez N, Sidoli S, Schmidt A Jensen ON, Imhof A, Groth A: Two distinct modes for propagation of histone PTMs across the cell cycle. Genes Dev 2015, 29:585-590.

52. Ramachandran S, Henikoff S: Transcriptional regulators compete with nucleosomes post-replication. Cell 2016, 165:580-592

53. Liu Z, Keller PJ: Emerging imaging and genomic tools for developmental systems biology. Dev Cell 2016, 36:597-610.

54. Bassel GW, Smith RS: Quantifying morphogenesis in plants in 4D. Curr Opin Plant Biol 2016, 29:87-94.

55. Efroni I, Mello A, Nawy T, Ip PL, Rahni R, DelRose N, Powers A, Satija R, Birnbaum KD: Root regeneration triggers an embryolike sequence guided by hormonal interactions. Cell 2016.
56. Ingouff M, Rademacher S, Holec S, Soljic L, Xin N, Readshaw A, Foo SH, Lahouze B, Sprunck S, Berger F: Zygotic resetting of the HISTONE 3 variant repertoire participates in epigenetic reprogramming in Arabidopsis. Curr Biol 2010, 20:2137-2143.

57. Yelagandula R, Stroud H, Holec S, Zhou K, Feng S, Zhong X, Muthurajan UM, Nie X, Kawashima T, Groth M et al:: The histone variant H2A.W defines heterochromatin and promotes chromatin condensation in Arabidopsis. Cell 2014, 158:98-109.

58. Kumar SV, Wigge PA: H2A.Z-containing nucleosomes mediate the thermosensory response in Arabidopsis. Cell 2010, 140:136-147.

59. Zemach A, Kim MY, Hsieh PH, Coleman-Derr D, Eshed-Williams L, Thao K, Harmer SL, Zilberman D: The Arabidopsis nucleosome remodeler DDM1 allows DNA methyltransferases to access H1-containing heterochromatin. Cell 2013, 153:193-205.

60. Rutowicz K, Puzio M, Halibart-Puzio J, Lirski M, Kotlinski M, Kroten MA, Knizewski L, Lange B, Muszewska A, SniegowskaSwierk $\mathrm{K}$ et al.: A specialized histone $\mathrm{H} 1$ variant is required for adaptive responses to complex abiotic stress and related DNA methylation in Arabidopsis. Plant Physiol 2015, 169:2080-2101.

61. Barth TK, Imhof A: Fast signals and slow marks: the dynamics of histone modifications. Trends Biochem Sci 2010, 35:618-626.

62. Mozgova I, Kohler C, Hennig L: Keeping the gate closed: functions of the polycomb repressive complex PRC2 in development. Plant J 2015, 83:121-132.

63. Cui X, Lu F, Qiu Q, Zhou B, Gu L, Zhang S, Kang Y, Ma X, Yao Q, Ma J et al.: REF6 recognizes a specific DNA sequence to demethylate H3K27me3 and regulate organ boundary formation in Arabidopsis. Nat Genet 2016, 48:694-699.

64. Li C, Gu L, Gao L, Chen C, Wei CQ, Qiu Q, Chien CW, Wang S, Jiang L, Ai LF et al:: Concerted genomic targeting of H3K27 demethylase REF6 and chromatin-remodeling ATPase BRM in Arabidopsis. Nat Genet 2016, 48:687-693.

65. Law JA, Jacobsen SE: Establishing, maintaining and modifying DNA methylation patterns in plants and animals. Nat Rev Genet 2010, 11:204-220

66. Stroud H, Do T, Du J, Zhong X, Feng S, Johnson L, Patel DJ, Jacobsen SE: Non-CG methylation patterns shape the epigenetic landscape in Arabidopsis. Nat Struct Mol Biol 2014, 21:64-72.

67. Matzke MA, Mosher RA: RNA-directed DNA methylation: an epigenetic pathway of increasing complexity. Nat Rev Genet 2014, 15:394-408.

68. Zhong X, Du J, Hale CJ, Gallego-Bartolome J, Feng S, Vashisht AA, Chory J, Wohlschlegel JA, Patel DJ, Jacobsen SE: Molecular mechanism of action of plant DRM de novo DNA methyltransferases. Cell 2014, 157:1050-1060. 